\title{
Sudden Cardiac Death in Young Athletes; a Literature Review and Special Considerations in Asia
}

\author{
Authors' Affiliation: \\ 1. Sports Medicine Research Center, \\ Tehran University of Medical \\ Sciences, Tehran, IR Iran \\ 2. Department of Sport and Exercise \\ Medicine, Faculty of Medicine, \\ Tehran University of Medical \\ Sciences, Tehran, IR Iran \\ * Corresponding Author; \\ Address: Sports Medicine Research \\ Center, Tehran University of Medical \\ Sciences, No 7, Al-e-Ahmad \\ Highway, Tehran, IR Iran \\ E-mail: fhalabchi@tums.ac.ir
}

Received: Jan 04, 2011

Accepted: Jan 27, 2011

Key Words: Athletes; Young Adult; Sudden Cardiac Death; Asia; Sports

\begin{abstract}
Sudden cardiac death (SCD) in a young athlete is rare, but catastrophic. Exercise acts as a risk factor for SCD in people with cardiovascular disease. A diversity of cardiovascular disorders including hypertrophic cardiomyopathy, congenital coronary anomalies, arrhythmogenic right ventricular dysplasia, dilated cardiomyopathy, aortic rupture due to Marfan syndrome, myocarditis, valvular disease and electrical disorders (Wolff-Parkinson-White syndrome, long QT syndrome, Brugada syndrome), as well as commotio cordis represent the common causes of SCD in young athletes.

As the outcome of lethal cardiovascular disorders is not reversible except in few cases, effective measures should be addressed to reduce the burden of sudden cardiac death in young athletes. Currently, two types of recommendations are proposed by American and European countries.

It seems that there are some special considerations in Asia, entirely different from North America or Europe, which warrant more comprehensive research on epidemiology and etiology of SCD in young Asian athletes by country and evaluation of current national preventive strategies and their achievements in decreasing the risk. Using these data and considering regional restrictions, an expert group will be able to plan a practical and feasible preventive strategy.
\end{abstract}

Asian Journal of Sports Medicine, Volume 2 (Number 1), March 2011, Pages: 1-15

\section{INTRODUCTION}

Sudden cardiac death (SCD) in an athlete is a rare, S but tragic event. Various definitions have been used for sudden cardiac death by different organizations or authors which in turn may affect the estimated prevalence among athletic populations ${ }^{[1-12]}$. American college of cardiology defines SCD as "nontraumatic and unexpected sudden death that may occur from a cardiac arrest, within 6 hours of a previously normal state of health",[1].
According to the World Health Organization definition, SCD refers to an unexpected death within 1 hour of symptom onset if witnessed or within 24 hours of being observed alive and symptom-free if unwitnessed ${ }^{[2]}$.

However, this definition includes many cases of well-established acute myocardial infarction, and therefore, should not be considered as sudden cardiac deaths ${ }^{[5]}$. Some other authors define SCD as death within $1 \mathrm{~h}$ of the onset of symptoms in someone without a previously recognised cardiovascular abnormality, 
excluding respiratory, cerebrovascular and drug related deaths ${ }^{[8,9]}$.

Sport related SCD was defined as non-traumatic SCD during or within 1 hour after moderate- to highintensity exercise in a competitive athlete. The deceased was considered a competitive athlete if he or she did physically demanding sports and took part in competitions ${ }^{[13]}$.

\section{EPIDEMIOLOGY}

Exercise acts as a trigger for sudden cardiac death in people with cardiovascular disease. The risk for sudden death in young athletes with cardiovascular disease is 2.5 times higher than that in non-athletes. Greater than $90 \%$ of sudden cardiac death occurs during or immediately after a training session or competition ${ }^{[15]}$.

The incidence of sudden cardiac death in any population including athletes varies depending on multiple parameters including sex, age, ethnic group, nationality, screening methods to reveal sudden death, and attempts to prevent or avert sudden death. It also depends upon the definition used and how the diagnosis is made ${ }^{[3]}$.

The incidence of SCD in the general population ( $>35$ years of age) is estimated to be 1 in 1000 persons per year ${ }^{[15]}$. In young people ( $<35$ years of age), the incidence of all sudden deaths (including non-cardiac causes) is $1.5-6.5$ per 100000 persons per year, and the incidence of SCD is $0.3-3.6$ per 100000 persons per year $^{[16-21]}$.

In US high-school and college athletes (age 12-24 years), the incidence of SCD has been found to be $0.5 / 100000$ participants per year ${ }^{[20]}$, whereas the incidence was found to be $3.6 / 100000$ in Italian competitive athletes (age 14-35 years) ${ }^{[21]}$. According to the National Center for Catastrophic Sport Injury Research in the USA, the rate of SCD is five times higher in male than female high-school and college athletes $\left(0.75\right.$ vs 0.13 per 100000 athletes per year ${ }^{[20]}$. Moreover, the estimated death rate is twice in college athletes (age ranging from 20 to 24 years) compared with their high school (age ranging between 12 and 19 years) counterparts ( 1.45 vs 0.66 per 100000 athletes per year) ${ }^{[20]}$.

Similar studies on Scandinavian people have reported that the incidence of deaths among physically active young men were 0.9 and 1.21 per 100000 athlete person-years in Norway and Denmark respectively ${ }^{[13,22]}$.

\section{COMMON CAUSES FOR SPORT RELATED SUDDEN CARDIAC DEATH}

A variety of cardiovascular abnormalities represent the most common causes of sudden death in competitive athletes. The specific pathologies responsible for athletic field catastrophes vary noticeably with regard to age. For example, in young athletes (younger than 35 years) the vast majority of sudden deaths are due to underlying cardiovascular abnormalities including hypertrophic cardiomyopathy, congenital coronary anomalies and arrhythmogenic right ventricular dysplasia (ARVD). These deaths occur most commonly in team sports such as basketball and football, which have the highest levels of participation ${ }^{[8,23,24]}$.

To a lesser extent, other abnormalities including dilated cardiomyopathy, aortic rupture in the context of Marfan syndrome, myocarditis, valvular disease (aortic stenosis, mitral valve prolapse) and electrical disorders (Wolff-Parkinson-White syndrome, long QT syndrome, Brugada syndrome), as well as commotio cordis (malignant arrhythmia due to blunt chest trauma) are responsible ${ }^{[8,10,25,26]}$. In athletes with more than 35 years of age that constitute the minority of professional athletes, the main cause of death is coronary artery disease as in the general population ${ }^{[24]}$.

\section{Hypertrophic Cardiomyopathy}

Hypertrophic cardiomyopathy (HCM) is the single most common cardiovascular cause of SCD in young athletes in the USA, accounting for $35 \%$ to $50 \%$ of cases $^{[14,24,26,27,28]}$. 
It is a primary and familial cardiac disease with heterogeneous clinical and morphological expression and a diverse clinical course ${ }^{[8]}$. The prevalence is about $0.2 \%$ in the general population ${ }^{[29]}$, whereas the prevalence is estimated to be $0.07 \%$ to $0.08 \%$ in screened athletes ${ }^{[30,31]}$. Sudden death from HCM is most common in children and young adults (under age 30 ), usually in individuals who previously have been asymptomatic (or only mildly symptomatic) ${ }^{[28,32,33]}$.

A remarkable sudden death in Mark Vivien Fue, a Cameroon soccer player which occurred during a televised international match was attributed to ventricular fibrillation due to $\mathrm{HCM}^{[34]}$.

Hence, these mortalities usually occur without warning signs and are often the first clinical manifestation of the disease, caused by ventricular arrhythmia $^{[26,35,36]}$.

Morphologically, $\mathrm{HCM}$ in young people is characterised by a spectrum of alterations including progressive left ventricular hypertrophy and myocardial disarray ${ }^{[8]}$.

The well documented physical findings of a bifid arterial pulse and a loud systolic heart murmur that increases in intensity from the Valsalva maneuver or standing are only present with left ventricular outflow obstruction, which occurs in only $25 \%$ of patients with $\mathrm{HCM}^{[14,30]}$.

Left ventricular outflow obstruction may also cause a decrease in cardiac output and cerebral blood flow, leading to syncope. Any athlete who presents with unexplained syncope during or after exertion should receive a thorough cardiac evaluation. Patients may also present with dyspnea on exertion, which is due to restricted left ventricular filling or chest pain secondary to subendocardial ischemia. The thickened ventricular wall and abnormal intramural vasculature limit regional coronary blood flow and oxygen delivery to the myocardium, resulting in ischemia and chest pain $^{[14,37]}$.

Sudden cardiac death from HCM is usually caused by primary ventricular tachycardia/fibrillation and can be the first clinical manifestation of the disease, usually in the context of exercise and sports participation ${ }^{[8,14]}$. The most reliable means for diagnosis of HCM is 2dimensional echocardiography. This will demonstrate a hypertrophic non-dilated left ventricle in the absence of other cardiac or systemic diseases capable of producing hypertrophy to the magnitude present ${ }^{[30,38]}$.

However, the echocardiographic appearance of abnormal ventricular wall thickening may not become apparent until adolescence. If $\mathrm{HCM}$ is strongly suspected, serial echocardiograms should be performed. Electrocardiography (ECG) may demonstrate evidences of left ventricular hypertrophy, showing bizarre patterns with strikingly increased voltages, prominent $\mathrm{Q}$ waves and/or deeply negative $\mathrm{T}$ waves $^{[14]}$.

Clinical diagnosis of HCM is generally based on the recognition of the disease phenotype with LV hypertrophy ${ }^{[27,28,32]}$. In this regard, a maximal LV enddiastolic wall thickness of $15 \mathrm{~mm}$ or more (or on occasion, 13 or $14 \mathrm{~mm}$ ) is the absolute dimension generally accepted for the clinical diagnosis of HCM in an adult athlete (in children, 2 or more standard deviations from the mean relative to body surface are; $z$-score of 2 or more). However, any LV wall thickness (including normal) is theoretically compatible with the presence of a mutant HCM gene $e^{[1,27,28,32]}$.

Athletes with a probable or unequivocal clinical diagnosis of HCM should be excluded from the most competitive sports with the possible exception of those with low intensity of static and dynamic load. This recommendation is independent of age, sex, and phenotypic appearance, and does not differ for those athletes with or without symptoms, LV outflow obstruction, or prior treatment ${ }^{[1]}$.

\section{Congenital Coronary Artery Anomaly}

The second most frequent cause of SCD in young athletes is a variety of congenital coronary artery anomalies which individually are quite rare, accounting for only $12 \%$ to $20 \%$ of SCD cases $^{[24,37,39]}$.

The most common of these malformations is anomalous origin of the left main coronary artery from the anterior (right) sinus of Valsalva, with an acute angled bend coursing between the pulmonary trunk and the anterior aspect of the aorta ${ }^{[40,41,42]}$.

Most patients with coronary artery anomalies are asymptomatic, and may die suddenly as the first manifestation of their abnormality. Those who are symptomatic rarely complain of typical angina, 
reporting nonspecific symptoms such as syncope, dyspnea on exertion and palpitations ${ }^{[43,44,45]}$. The vast majority of these symptoms are related to exertion. Myocardial ischaemia is precipitated by exercise because of critically impaired coronary flow due to an abnormal, slit-like ostium of the anomalous coronary artery, compression of the anomalous artery between the pulmonary artery and ascending aorta, or possibly coronary spasm triggered by endothelial dysfunction $^{[45]}$.

Transthoracic echocardiography may be useful in diagnosis. However, highly trained ultrasound technicians using high-quality imaging systems are required for accurate and consistent identification of the origin of the coronary arteries ${ }^{[44]}$. Coronary arteriography is indicated if other studies are not diagnostic. Surgery is usually performed when the diagnosis is made ${ }^{[46]}$.

Detection of coronary anomalies of wrong sinus origin warrants the complete exclusion from participating in competitive sports. Three months after successful operation, an athlete without ischemia, arrhythmia, or dysfunction during maximal exercise testing can participate in all sports ${ }^{[40]}$.

\section{Arrhythmogenic Right Ventricular Dysplasia (Arvd)}

ARVD is an inherited myocardial disease that predominantly affects the right ventricle and, less commonly, the left ventricle $e^{[8,25]}$. Pathologically, ARVD is characterised by progressive death of myocardial cells with subsequent fibro-fatty replacement, and clinically by ventricular and supraventricular arrhythmias resulting in $\mathrm{SCD}^{[47,48]}$.

In patients with ARVD, the risk of SCD is 5.4 times higher during competitive sports than during sedentary activity $^{[25]}$. Triggering mechanisms for arrhythmias include increased afterload during exercise and hypersensitivity to catecholamines due to damage of sympathetic nerve trunks ${ }^{[8,47,49]}$.

In each adolescent or young individual with palpitations, syncope, aborted sudden death or ventricular tachycardia (VT) of left bundle branch block morphology, ARVD should be suspected ${ }^{[8,49]}$. ECG changes such as $\mathrm{T}$ wave inversion in $\mathrm{V} 1-\mathrm{V} 3$ or premature ventricular complexes of left bundle branch block morphology should also arouse suspicion of ARVD, even in asymptomatic individuals ${ }^{[49]}$. The routine assessment of patients with suspected ARVD include clinical and family history, physical examination, chest radiography, 12-lead ECG, 24-hour ambulatory ECG, signal-averaged ECG, stress test, and two-dimensional echocardiography ${ }^{[49,50]}$. Due to limited ability of ECG and echocardiography to differentiate ARVD from benign physiological changes, magnetic resonance imaging may offer increased sensitivity for this diagnosis ${ }^{[14,51]}$. Athletes with probable or definite diagnosis of ARVD should be excluded from most competitive sports, with the possible exception of those of low static and dynamic intensity ${ }^{[1]}$.

\section{Marfan Syndrome}

Marfan syndrome is an autosomal dominant genetic disease with variable penetrance, mostly caused by a mutation in the fibrillin-1 gene on chromosome 15. It has an increased risk for sudden death due to aortic dissection ${ }^{[14,52,53]}$. It is characterized clinically by a diverse constellation of abnormalities variable in severity and involving primarily the ocular, skeletal, and cardiovascular organ systems ${ }^{[1,54]}$.

The disease has an estimated incidence of 1 in 5000-7000 and has been shown to be more common in taller athletes such as basketball and volleyball players because tallness is one of the phenotypic expressions of the syndrome ${ }^{[52,55,56]}$.

Diagnosis is made according to the Ghent nosology if major criteria are present in two organ systems and a third is involved, or when there is a family history of Marfan syndrome ${ }^{[1,54]}$. Skeletal abnormalities include arm span to height ratio greater than 1.05 , tall stature, arachnodactyly, hyperextensibility and ligamentous laxity, scoliosis, and chest wall deformity (pectus excavatum or carinatum), in addition to ectopia lentis (lens dislocation).

Cardiovascular manifestations that impact on prognosis consist of progressive dilatation of the aortic root or descending aorta which are predisposed to dissection and rupture ${ }^{[57]}$; and mitral valve prolapse with associated mitral regurgitation or LV systolic dysfunction, which may occasionally be predisposed to ventricular tachyarrhythmias and sudden death ${ }^{[58]}$. 
Echocardiography can be used to measure and monitor the degree of aortic root dilation ${ }^{[14,53]}$. The risk for aortic rupture is usually linked to marked enlargement of the aorta (transverse dimension greater than $50 \mathrm{~mm}$ ). However, dissection can also occur with a normal (or near-normal) aortic root dimension ${ }^{[1,58]}$. Weightlifting has been specifically associated with aortic dissection in athletes. The incidence of aortic dissection appears to decrease with earlier prophylactic surgical aortic root reconstruction and beta-blocker therapy ${ }^{[1]}$.

Athletes with Marfan syndrome can participate in low and moderate static/low dynamic competitive sports if they do not have any of the aortic root dilatation or moderate-to-severe mitral regurgitation or family history of dissection or sudden death in a Marfan relative.

It is recommended, however, that these athletes have an echocardiographic measurement of aortic root dimension repeated every six months for close surveillance of aortic enlargement ${ }^{[1,55]}$.

\section{Myocarditis}

Myocarditis is an inflammatory disease associated with cardiac dysfunction and it is diagnosed by established histological, immunological, and immunohistochemical criteria". It is characterized by the histologic evidence of inflammatory infiltration associated with myocyte degeneration and necrosis of non-ischemic origin ${ }^{[59]}$. Viral infection is the most common cause of myocarditis, with coxsackie B virus implicated in 50\% of cases ${ }^{[39,51,60]}$.

Myocarditis increases the risk for sudden death, which may occur during both active and healing phases of the illness ${ }^{[51]}$ and accounts for 3-7\% of SCDs related to sports ${ }^{[8,20,21,26]}$. Myocarditis may be clinically silent until sudden death occurs, or it may present with dyspnea, fatigue, exercise intolerance, palpitations, syncope or presyncope, or symptoms of congestive heart failure such as orthopnea ${ }^{[39,60]}$.

The clinical evaluation of patients with suspected myocarditis includes a personal and family history (especially the evidence of fever and flu-like illness, or previous viral infection), physical examination, 12-lead ECG, and echocardiography ${ }^{[59,61]}$. The ECG changes include frequent, complex ventricular or supraventricular arrhythmias, ST-T segment depression, Twave inversion, and left bundle branch or atrioventricular blocks ${ }^{[61]}$. Additional testing (such as 24-hour ECG monitoring) may be required according to the specific case ${ }^{[61]}$.

Athletes with a clinical diagnosis of myocarditis should be temporarily excluded from competitive and leisure time sport activity. This recommendation is independent of age, gender, presenting symptoms and selected treatments. After resolution of disease (at least 6 months after the onset of the disease), clinical reassessment is indicated before the athlete returns to a competitive sport lifestyle. Furthermore, preparticipation evaluation should be performed every 6 months during the follow-up ${ }^{[1,59]}$.

\section{Wolff-Parkinson-White syndrome (WPW)}

Wolff-Parkinson-White syndrome is defined as the presence of paroxysmal arrhythmias in a patient with ventricular pre-excitation due to an accessory pathway ${ }^{[8,62]}$. The prevalence of pre-excitation in athletes is $0.1-0.3 \%$, similar to that of the general population ${ }^{[63]}$. Most patients with pre-excitation are asymptomatic, but when symptoms do occur, they are usually derived from tachyarrhythmias such as atrial or ventricular fibrillation ${ }^{[62,64]}$.

Required studies consist of 12-lead ECG, exercise test and echocardiography to exclude associated cardiovascular disorders. In some cases, a 24-h ECG holter monitoring during athletic activity may be indicated. Electrophysiologic studies are indicated in athletes with symptoms of impaired consciousness, long-term palpitations, or rapid rates in whom an ablation procedure is indicated.

In asymptomatic athletes with no history of palpitations or tachycardia and no evidence of structural cardiac abnormalities, further assessment may not be required. However, the optimal management for these athletes is not verified ${ }^{[65,66]}$. Among individuals with multiple accessory pathways or ventricular rates exceeding 240 beats/min, catheter ablation of the accessory pathway should be considered ${ }^{[65,67]}$. For those athletes with a history of palpitations, syncope or near syncope, further assessment is 
mandatory ${ }^{[64]}$.

\section{Congenital long QT syndrome}

The term congenital long QT syndrome (LQTS) includes a constellation of inherited disorders caused by cardiac ion channel mutations, which produce prolonged ventricular repolarization and a tendency to polymorphic ventricular tachycardia ${ }^{[8,68,69,70]}$. LQTS may manifest as palpitation, presyncope, syncope, seizure, cardiac arrest and/or SCD in young individuals and is often associated with exercise ${ }^{[24,68,70]}$.

The QT interval is typically measured in lead II of a 12-lead ECG and corrected for rate by using Bazett's formula $(\mathrm{QTc}=\mathrm{QT} / \sqrt{\mathrm{RR}})$. LQTS is defined as a corrected QT interval $>440 \mathrm{~ms}$ in men and $>460 \mathrm{~ms}$ in women $^{[68,71]}$, but intervals of $>470 \mathrm{~ms}$ and $>480 \mathrm{~ms}$ have also been suggested ${ }^{[72]}$ indicating the lack of welldefined optimal cut-off value. Extreme QT prolongation (usually $500 \mathrm{~ms}$ ) predisposes cases to torsade de pointes and ventricular fibrillation ${ }^{[73]}$.

The incidence of cases of SCD due to LQTS in young athletes is estimated to be from $0.5 \%$ to $8 \%{ }^{[6,21,}$ ${ }^{26]}$. Guidelines are more restrictive and specific for competitive compared with recreational sports. According to the 36th Bethesda conference, athletes who have suffered a cardiac arrest and/or a syncopal episode because of LQTS should be excluded from participation in competitive sports, except those sports with low dynamic and static component (golf, as well as billiards, bowling, cricket, curling, and riflery ${ }^{[74]}$.

Asymptomatic athletes with definite QT prolongation in their surface ECG $(>470 \mathrm{~ms}$ in males, $>480 \mathrm{~ms}$ in females) should also be disqualified from all but class IA competitive sports ${ }^{[64]}$. In contrast to the Bethesda conference, the European conservative approach excludes any individual with LQTS from all competitive sports participation ${ }^{[73]}$.

\section{Brugada Syndrome}

This is an autosomal dominant cardiac sodium channelopathy $^{[8,68]}$, which clinically presents with syncope or less commonly with ventricular fibrillation leading to $\mathrm{SCD}^{[73]}$. Although the disease is recognized worldwide, the prevalence seems much higher in some areas, especially in Southeast Asia. Prevalence ranging from 5 to 66 per 10000 has been reported ${ }^{[76]}$.

Electrocardiographically, it is characterized by accentuated $J$ wave primarily in leads V1 through V3 with ST-segment elevation, often followed by a negative $\mathrm{T}$-wave and an $\mathrm{R}$ prime which is unrelated to ischemia, electrolyte disturbances, or obvious structural heart disease $\mathrm{e}^{[76,77,78]}$.

The accentuated $\mathrm{J}$ wave simulates an $\mathrm{R}^{\prime}$ and gives the appearance of right bundle branch block. The $\mathrm{R}^{\prime}$ in Brugada syndrome is thought to be due to early repolarisation of the right ventricular epicardium rather than the right bundle branch block ${ }^{[79]}$.

Hyperthermia can potentially uncover the Brugada ECG pattern in patients with Brugada syndrome, who can then display fever-induced polymorphic ventricular arrhythmia. Death often occurs with mild activity or during sleep. Although an obvious relation between exercise and sudden death has not been recognized, and because of the potential effect of hyperthermia, restriction to participation in sports with low static and dynamic intensity seems advisable ${ }^{[64]}$.

\section{Commotio Cordis}

Commotio cordis is a primary arrhythmic event that occurs when the mechanical energy generated by a blow is confined to a small area of the precordium (particularly at or near the center of the cardiac silhouette) and profoundly alters the electrical stability of the myocardium, resulting in ventricular fibrillation [80,81,82].

About $50 \%$ of commotio cordis events have been reported in young competitive athletes (mostly those between 11 and 20 years of age) participating in a variety of organized amateur sports -typically baseball, softball, ice hockey, football, or lacrosse- who receive a blow to the chest that is usually (but not always) delivered by a projectile used to play the game. It may also result from physical contact between competitors $[80,82,83,84]$.

The timing of the blow is also important, which must occur during an electrically vulnerable period within a narrow window of 10 to $20 \mathrm{msec}$ on the upstroke of the $\mathrm{T}$ wave, just before its peak (accounting for only $1 \%$ of the cardiac cycle) ${ }^{[82,85]}$. 
The survival rate is poor, as low as about $15 \%$, likely due to lack of early recognition and the failure to initiate timely aggressive resuscitation. Survival is most likely to occur with the institution of cardiopulmonary resuscitation and defibrillation within 3 minutes of the incidental event ${ }^{[80,82]}$.

\section{ILLICIT DRUGS AND SCD}

Some prohibited substances, especially anabolic steroids, stimulants and peptide hormones, may cause a wide range of cardiac arrhythmias (focal or reentry type, supraventricular and/or ventricular), even in healthy subjects with no previous history of cardiac diseases. Therefore, physicians should always take into consideration the possibility of illicit drug abuse as the cause of lethal arrythmia, especially if no signs of cardiac diseases are present ${ }^{[86,87,88]}$.

\section{PREVENTIVE STRATEGIES}

As common sence indicates "An ounce of prevention is worth a pound of cure" and because the oucome of lethal cardiovascular disoders is not reversible except in few cases, effective and efficient measures should be addressed to reduce the burden of sudden cardiac death in young athletes. Nowadays two types of recommendations are proposed, each is propagated by American and European countries.

\section{AMERICAN APPROACH}

In 1996, the American Heart Association (AHA) released a scientific statement advocating universal cardiovascular preparticipation screening for young athletes in an attempt to identify those who are vulnerable to cardiovascular events ${ }^{[23]}$. The recommendations included a 12-element complete history and physical examination (including blood pressure measurement) before competitive sports (Table 1) and reserved non-invasive testing such as a 12-lead ECG, echocardiography, exercise testing, and cardiovascular consultation for athletes with detected abnormality ${ }^{[89,90]}$.

The recommendations included cardiovascular screening every 2 years with an abbreviated examination in intervening years. The committee recommended a national standard for preparticipation cardiovascular medical evaluation and education of all healthcare providers who screen athletes. Routine diagnostic tests (ie, ECG) as part of the screening were excluded primarily for cost-efficacy considerations ${ }^{[90]}$.

In 2007 update, the AHA 12-element recommendations remained unchanged and did not include universal 12-lead ECG recordings as part of preparticipation history and physical examination, unless the athlete fails the 12-element examination. These recommendations have also been endorsed by American College of Cardiology Foundation ${ }^{[89]}$. However, it seems that elderly competitive athletes should be assessed with more caution ${ }^{[89,91]}$.

These recommendations rely greatly on cost efficacy studies in USA. For example, AHA experts have assumed that in USA, about 10 million high school and middle school athletes would be eligible for annual screening with costs (based on Center for Medicare Services-approved reimbursements) of \$25 for each personal and family history and physical examination and $\$ 50$ for each ECG. Consequently, the expense for the primary evaluations would be $\$ 750$ million. In addition, positive results in history, physical examination, or ECG could be expected to affect approximately $15 \%$ of the 10 million screened athletes (1.5 million $)^{[30,89,92]}$. This would justify a non-invasive evaluation including another visit by cardiologist (\$100) and 2-dimensional echocardiography $(\$ 400)$.

This secondary evaluation would add about $\$ 750$ million to the cost of the program each year, which would make the minimum annual total of $\$ 1.5$ billion. However, this analysis does not consider all the substantial administrative resources and costs necessary to operate a program of this magnitude and other medical expenses in selected athletes suspected 
Table 1: The 12-Element AHA Recommendations for Preparticipation Cardiovascular Screening of Competitive Athletes ${ }^{\text {[89] }}$

\section{Medical history* \\ Personal history}

1. Exertional chest pain/discomfort

2. Unexplained syncope/near syncope $\dagger$

3. Excessive exertional and unexplained dyspnea/fatigue associated with exercise

4. Prior recognition of a heart murmur

5. Elevated systemic blood pressure

\section{Family history}

6. Premature death (sudden and unexpected or otherwise) before $50 \mathrm{y}$ of age resulting from heart disease in 1 relative

7. Disability from heart disease in a close relative $50 \mathrm{y}$ of age

8. Specific knowledge of certain cardiac conditions in family members: hypertrophic or dilated cardiomyopathy, long-QT syndrome or other ion channelopathies, Marfan syndrome, or clinically important arrhythmias

\section{Physical examination}

9. Heart murmurt

10. Femoral pulses to exclude aortic coarctation

11. Physical stigmata of Marfan syndrome

12. Brachial artery blood pressure (sitting position)§

*Parental verification is recommended for high school and middle school athletes.

$\dagger$ Judged not to be neurocardiogenic (vasovagal); of particular concern when related to exertion.

†Auscultation should be performed in both supine and standing positions (or with Valsalva maneuver), specifically to identify murmurs of dynamic left ventricular outflow tract obstruction.

§Preferably taken in both arms.

of having cardiovascular disease. It would add another $\$ 500$ million to the overall cost, for an annual total of $\$ 2.0$ billion.

By using the known prevalence of diseases such as $\mathrm{HCM}, \mathrm{ARVD}$, and ion channelopathies in the general population (conservatively $1: 1000$ ), it can be supposed that $\approx 10000$ athletes (of the 10 million) would harbor these latent cardiac diseases that are eventually detectable by screening with $\mathrm{ECG}^{[89]}$.

Of these 10000 athletes, around 9000 are likely to have an abnormal ECG pattern that would raise suspicion of cardiac disease during the screening process. Given the theoretical cost of a mass cardiovascular screening program of $\$ 2$ billion per year, the dollar expenditure linked to detecting each athlete with the suspected relevant cardiac diseases would be $\$ 330000$. With this assumption that about $10 \%$ of these 9000 athletes with cardiac disease (900) would harbor evidence of increased risk for sudden death $^{[93]}$, the cost of preventing each theoretical death would be $\$ 3.3$ million $^{[89]}$. According to these calculations, experts concern the practicality and feasibility of establishing a continuous annual national program for many years at a cost of approximately $\$ 2$ billion per year ${ }^{[89]}$.

\section{EUROPEAN APPROACH}

The European Society of Cardiology (ESC) and the International Olympic Committee (IOC) screening questionnaires serve an aim similar to that of the 12element AHA questionnaire, although they include more questions and the content is slightly different (Table 2) ${ }^{[90,94]}$. However, the prescreening strategy of the ESC and IOC is quite different and universal 12lead rest ECG is recommended for athletes $<35$ years, leading to a significant controversy between the American and European positions on the need for routine ECG recording ${ }^{[95]}$.

The IOC-ESC consensus relied mainly on the 25year Italian experience of systematic preparticipation screening of competitive athletes. In 1982, the Italian 
Table 2: Recommended assessment for all participants at the beginning of competitive activities until 35 years of age (ESC \& IOC) ${ }^{[94]}$

\section{Medical History}

\section{Personal History:}

Have you ever fainted or passed out when exercising?

Do you ever have chest tightness?

Does running ever cause chest tightness?

Have you ever had chest tightness, cough, or wheezing that made it difficult for you to perform sports?

Have you ever been treated/hospitalized for asthma?

Have you ever had a seizure?

Have you ever been told that you have epilepsy?

Have you ever been told to give up sports because of health problems?

Have you ever been told that you have high blood pressure?

Have you ever been told that you have high cholesterol?

Do you have trouble breathing or do you cough during or after activity?

Have you ever been dizzy during or after exercise?

Have you ever had chest pain during or after exercise?

Do you have or have you ever had racing of your heart or skipped heartbeats?

Do you get tired more quickly than your friends during exercise?

Have you ever been told that you have a heart murmur?

Have you ever been told that you have a heart arrhythmia?

Do you have any other history of heart problems?

Have you had a severe viral infection (e.g., myocarditis or mononucleosis) within the last month?

Have you ever been told that you had rheumatic fever?

Do you have any allergies?

Are you taking any medications at the present time?

Have you routinely taken any medication in the past 2 years?

\section{Family history:}

Has anyone in your family with less than 50 years of age:

Died suddenly and unexpectedly?

Been treated for recurrent fainting?

Had unexplained seizure problems?

Had unexplained drowning while swimming?

Had unexplained car accident?

Had heart transplantation?

Had pacemaker or defibrillator implanted?

Been treated for irregular heart beat?

Had heart surgery?

Has anyone in your family experienced sudden infant death (cot

death)?

Has anyone in your family been told they have Marfan syndrome?

\section{Physical examination}

\section{General}

Radial and femoral pulses

Marfan stigmata

\section{Cardiac auscultation}

Rate/rhythm

Murmur: systolic/diastolic

Systolic click

Blood pressure

\section{Diagnostic tests}

12-lead resting ECG (after the onset of puberty)

From the ESC and the IOC Meeting on Sudden Cardiovascular Death in Sport, Lausanne, Switzerland, December 9 to 10 , 2004; Lausanne recommendations adopted.

ESC: European Society of Cardiology/ IOC: International Olympic Committee / ECG: Electrocardiography 
government passed a law to insist on preparticipation evaluation including at least a general physical examination, a 12-lead ECG, and submaximal exercise test for all athletes participating in organized competitive athletic events and that the screening protocol should be conducted annually ${ }^{[96]}$.

Based on Italian law, it is the responsibility of the physician to reveal, with a reasonable degree of medical certainty, whether an athlete is free of potentially lethal cardiovascular abnormalities during athletic activities. In 2006, a report of Italian experience using the screening process showed that the annual incidence of sudden cardiac death in young athletes (12-35 years old) decreased from 3.6 deaths per 100000 person-years in 1979 to 1981 to 0.4 deaths per 100000 person-years in 2003 to 2004, an $89 \%$ reduction. However, no change occurred in the mortality rates among the unscreened non-athletic population $^{[21]}$. In this report, $9 \%$ of screened athletes required additional cardiovascular testing, and $2 \%$ were ultimately prohibited from athletic participation.

The significant reduction in mortality with implementation of more aggressive screening may lead to the conclusion that this screening approach should be applied universally in all countries. However, there may be some limitations in this report ${ }^{[97]}$. Indeed, ECG may bear considerable advantages. Certain ECG findings are characteristic in $\mathrm{HCM}^{[30,98,99]}$ and it is stated that the ECG would be abnormal in $90-95 \%$ of these patients ${ }^{[28,90]}$. In addition, some authors have reported that an abnormal ECG is an early marker that may precede the appearance of left ventricular hypertrophy on the echocardiogram and symptoms ${ }^{[100,101]}$. In Italian preparticipation study, the ECG had a $77 \%$ greater power to detect HCM than the history and physical examination alone ${ }^{[30]}$.

Among the other cases of SCA in this age group, $80 \%$ of patients with arrhythmogenic right ventricular dysplasia have ECG abnormalities, as do high proportions of patients with long-QT and Brugada syndromes and dilated cardiomyopathy ${ }^{[98,102-104]}$. However, other conditions associated with sudden death during exercise such as Marfan syndrome, coronary artery anomalies, or catecholamine-induced ventricular tachycardia might not be detected with a resting $\mathrm{ECG}^{[90]}$.
Proponents of Italian approach believe that all of the reports on the cost-effectiveness of ECG studies, whether in Japan, Italy, or the United States, have shown a cost per year of life saved well below the $\$ 50$ 000 , figure that is used in public health policy discussions ${ }^{[98]}$. Of course, preventive strategies of SCD in athletes should be programmed largely by regionspecific financial, political, and cultural factors ${ }^{[105]}$.

\section{SPECIAL CONSIDERATIONS IN ASIA}

It seems that there are some special considerations in Asia, quite different from North America or Europe, which necessitates more comprehensive research on epidemiology and etiology of SCD in young Asian athletes by country and assessment of current national preventive strategies and their success to reduce the risk $^{[106]}$. Of course, selection of the preferred method for preparticipation evaluation of competitive athletes should keep these valuable data in consideration and modifications should be applied.

There are some of these considerations:

1- Asia is the world's largest and most populous continent. It hosts $60 \%$ of the world's current human population with approximately 4 billion people $^{[107]}$. Furthermore, the population is growing exponentially especially in developing countries of $\mathrm{Asia}^{[108]}$. For this reason, more young athletes exist in these countries in comparison with North American and European countries.

2- A significant incongruity exists between Asian countries regarding economic, cultural and health parameters. For example, some of Asian countries lie in the top of the world's gross domestic product (GDP) ranking and others in the bottom of the above mentioned rankings ${ }^{[109]}$. Hence, the economic burden of screening methods in competitive athletes would have completely diverse meanings.

3- Popular sports in different countries of Asia are quite different. Some of these popular sports such as Karate, Taekwondo, Judo, Kabedi, Free-style Wrestling, and Cricket, some of which originated in Asia, are among combat sport disciplines which 
may bear the potential risk for commotio cordis as a cause of $\mathrm{SCD}^{[80-85]}$.

4- Due to diverse ethnic origins ${ }^{[110]}$, the epidemiology of the most prevalent cause of sudden death may be different in comparison with USA or Europe. For example, ARVD has reported to be the most common cause of sudden cardiac death in young people ( $42 \%$ of cases) in an area of southeastern Korea $^{[111]}$. In other studies from Japan and southern Iran, the frequency of a Brugada-type ECG pattern is cited to be higher than some European countries $^{[112-114]}$. On the other hand, the data regarding the epidemiology and pathologic causes of SCD are unfortunately scarce, especially in deprived developing countries.

5- The cost of medical services including medical visit by general physician or cardiologist, ECG and echocardiography may be quite different in comparison with European and American countries as well as between Asian countries. For example, based on the rules of medical council of Iran for Medicare Services, the costs for visit of general physician, cardiologist, ECG and 2-dimensional echocardiography are $\$ 7, \$ 12, \quad \$ 4$ and $\$ 30$ respectively which are much lower compared with medical costs both in American and european countries $^{[30,89,92,98]}$.

6- The coverage of national health insurance services may be completely different in different parts of Asia.

According to these considerations, it seems prudent to encourage and support epidemiological studies regarding incidence and etiology of SCD in different countries of Asia and establish an efficient data registry and report system for SCD cases among young athletes based on a single accepted definition and well defined postmortem studies. It seems that intimate international collaboration is necessary for inclusion of such a registration system and integrated approach in the process of reporting sudden deaths in Asia region.

Using these data and considering regional restrictions, an expert group from all parts of Asia as well as recognized American and European experts will be able to plan a practical and feasible preventive strategy and design a screening evaluation program compatible with special needs and limitations of different countries in Asia.

\section{REFERENCES}

1. Maron BJ, Ackerman MJ, Nishimura RA, et al. Task Force 4: HCM and Other Cardiomyopathies, Mitral Valve Prolapse, Myocarditis, and Marfan Syndrome. J Am Coll Cardiol. 2005;45(8):1340-5.

2. Chugh SS, Jui J, Gunson K, et al. Current burden of sudden cardiac death: multiple source surveillance versus retrospective death certificate-based review in a large U.S. community. J Am Coll Cardiol. 2004;44:1268-75.

3. Fishbein MC. Cardiac disease and risk of sudden death in the young the burden of the phenomenon. Cardiovasc Pathol 2010;19:326-8.

4. Goldberger JJ, Cain ME, Hohnloser SH, et al. American Heart Association/American College of Cardiology Foundation/Heart Rhythm Society scientific statement on noninvasive risk stratification techniques for identifying patients at risk for sudden cardiac death. A scientific statement from the American Heart Association council on clinical cardiology committee on electrocardiography and arrhythmias and council on epidemiology and prevention. Circulation 2008;118:1497-518.

5. Virmani R, Burke AP, Farb A. Sudden cardiac death. Cardiovasc Pathol 2001;10:275-82.

6. Puranik R, Chow CK, Duflou JA, et al. Sudden death in the young. Heart Rhythm 2005;2:1277-82.

7. Basso C, Calabrese F, Corrado D, Thiene G. Postmortem diagnosis in sudden cardiac death victims: macroscopic, microscopic and molecular findings. Cardiovasc Res 2001;50:290-300.

8. Borjesson M, Pelliccia A. Incidence and aetiology of sudden cardiac death in young athletes: an international perspective. $\mathrm{Br}$ J Sports Med 2009;43:644-8.

9. Montagnana M, Lippi G, Franchini M, et al. Sudden cardiac death in young athletesreview. Intern Med. 2008;47:1373-8. 
10. Burke AP, Farb A, Virmani R, et al. Sports-related and non-sports-related sudden cardiac death in young adults. Am Heart J $1991 ; 121: 568-75$.

11. Wren C. Screening children with a family history of sudden cardiac death. Heart 2006;92:1001-6.

12. Amital H, Glikson M, Burstein M, et al. Clinical characteristics of unexpected death among young enlisted military personnel: results of a three-decade retrospective surveillance. Chest 2004;126:528-33.

13. Holst AG, Winkel BG, Theilade J, et al. Incidence and etiology of sports-related sudden cardiac death in DenmarkImplications for preparticipation screening. Heart Rhythm 2010;7:1365-71.

14. Shirley KW, Adirim TA. Sudden Cardiac Death in Young Athletes. Clin Ped Emerg Med 2005;6:194-9.

15. Sen-Chowdhry S, McKenna WJ. Sudden cardiac death in the young: a strategy for prevention by targeted evaluation. Cardiology 2006;105:196-206.

16. Molander N. Sudden natural death in later childhood and dolescence. Arch Dis Child 1982;57:572-6.

17. Driscoll DJ, Edwards WD. Sudden unexpected death in children and adolescents. J Am Coll Cardiol 1985;5:118B-21B.

18. Neuspiel DR, Kuller LH. Sudden and unexpected natural death in childhood and adolescence. JAMA 1985;254:1321-5.

19. Maron BJ, Gohman TE, Aeppli D. Prevalence of sudden cardiac death during competitive sports activities in Minnesota high school athletes. J Am Coll Cardiol 1998;32:1881-4.

20. van Camp SP, Bloor CM, Mueller FO, et al. Nontraumatic sports death in high school and college athletes. Med Sci Sports Exerc 1995;27:641-7.

21. Corrado D, Basso C, Pavei A, et al. Trends in sudden cardiovascular death in young competitive athletes after implementation of a preparticipation screening programme. JAMA 2006;296:1593-601.

22. Solberg EE, Gjertsen F, Haugstad E, KolsruddEur L. Sudden death in sports among young adults in Norway. J CardiovasC Prev Rehabil 2010;17:337-41.

23. Maron BJ, Thompson PD, Puffer JC, et al. Cardiovascular Preparticipation Screening of Competitive Athletes. Circulation 1996;94:850-56.

24. Maron BJ. Sudden death in young athletes. N Engl J Med 2003;349:1064-75.

25. Corrado D, Basso C, Rizzoli G, et al. Does sports activity enhance the risk of sudden death in adolescents and young adults? J Am Coll Cardiol 2003;42:1959-63.

26. Maron BJ, Doerer JJ, Haas TS, et al. Profile and frequency of sudden death in 1463 young competitive athletes: from a 25 year U.S: national registry: 1980-2005. Circulation 2006;114:830.

27. Maron BJ. Hypertrophic Cardiomyopathy and Other Causes of Sudden Cardiac Death in Young Competitive Athletes, with Considerations for Preparticipation Screening and Criteria for Disqualification. Cardiol Clin. 2007; 25:399-414

28. Maron BJ. Hypertrophic cardiomyopathy: A systematic review. JAMA 2002;287:1308-20.

29. Maron BJ, Gardin JM, Flack JM, et al. Prevalence of hypertrophic cardiomyopathy in a general population of young adults. Echocardiographic analysis of 4111 subjects in the CARDIA Study. Circulation 1995;92:785-9.

30. Corrado D, Basso C, Schiavon M, et al. Screening for hypertrophic cardiomyopathy in young athletes. $N$ Engl J Med 1998;339:364-9.

31. Basavarajaiah S, Wilson M, Whyte G, et al. Prevalence of hypertrophic cardiomyopathy in highly trained athletes. $J$ Am Coll Cardiol 2008;51:1033-9.

32. Maron BJ, McKenna WJ, Danielson GK, et al. American College of Cardiology/European Society of Cardiology clinical expert consensus document on hypertrophic cardiomyopathy. A report of the American College of Cardiology Task Force on Clinical Expert Consensus Documents and the European Society of Cardiology Committee for Practice Guidelines Committee to Develop an Expert Consensus Document on Hypertrophic Cardiomyopathy. J Am Coll Cardiol 2003;42:1687713.

33. Spirito P, Seidman CE, McKenna WJ, et al. The management of hypertrophic cardiomyopathy. $N$ Engl J Med 1997;336:775-85.

34. Maron BJ. How should we screen competitive athletes for cardiovascular disease? Eur Heart J. 2005;26:428-430.

35. Maron BJ, Pelliccia A. The heart of trained athletes: cardiac remodeling and the risks of sports including sudden death. Circulation 2006;114:1633-44.

36. Ostman-Smith I, Wettrell G, Keeton B, et al. Age- and gender-specific mortality rates in childhood hypertrophic cardiomyopathy. Eur Heart J 2008;29:1160-7.

37. Fuller CM. Cost effectiveness analysis of screening of high school athletes for risk of sudden cardiac death. Med Sci Sports Exerc 2000;32:887-90. 
38. Pfister GC, Puffer JC, Maron BJ. Preparticipation cardiovascular screening for US collegiate student-athletes. JAMA 2000;283:1597-9.

39. Trusty JM, Beinborn DS, Jahangir A. Dysrhythmias and the athlete. AACN Clin Issues 2004;15:432-48.

40. Graham TP, Driscoll DJ, Gersony WM, et al. Task Force 2: Congenital Heart Disease. J Am Coll Cardiol 2005;45:1326-33.

41. Basso C, Maron BJ, Corrado D, Thiene G. Clinical profile of congenital coronary artery anomalies with origin from the wrong aortic sinus leading to sudden death in young competitive athletes. J Am Coll Cardiol 2000;35:1493-501.

42. Davis JA, Cecchin F, Jones TK, Portman MA. Major coronary artery anomalies in a pediatric population: incidence and clinical importance. J Am Coll Cardiol 2001;37:593-7.

43. Maron BJ. The athlete's heart and cardiovascular disease: risk profiles and cardiovascular preparticipation screening of competitive athletes. Cardiol Clin 1997;15:473-83.

44. Zeppilli P, dello Russo A, Santini C, et al. In vivo detection of coronary artery anomalies in asymptomatic athletes by echocardiographic screening. Chest 1998;114:89-93.

45. Angelini P. Coronary artery anomalies. An entity in search of an identity. Circulation. 2007;115:1296-305.

46. Romp RL, Herlong JR, Landolfo CK, et al. Outcome of unroofing procedure for repair of anomalous aortic origin of left or right coronary artery. Ann Thorac Surg 2003;76:589-95.

47. Marcus F, Nava A, Thiene G. Arrhythmogenic right ventricular cardiomyopathy/dysplasia: recent advances. Milano: Springer. 2007.

48. Wichter $\mathrm{T}$, Hendricks $\mathrm{G}$, Lerch $\mathrm{H}$, et al. Regional myocardial sympathetic dysinnervation in arrhythmogenic right ventricular cardiomyopathy. Circulation 1994;89:667-83.

49. Basso C, Corrado D, Marcus FI, et al. Arrhythmogenic right ventricular cardiomyopathy. Lancet 2009;373:1289-300.

50. Firoozi S, Sharma S, Hamid MS, et al. Sudden death in young athletes: HCM or ARVC? Cardiovasc Drugs Ther 2002;16:11-7.

51. Maron BJ, Pelliccia A, Spirito P. Cardiac disease in young trained athletes. Circulation 1995;91:1596-601.

52. Kinoshita N, Mimura J, Obayashi C, et al. Aortic root dilatation among young competitive athletes: echocardiographic screening of 1,929 athletes between 15 and 34 years of age. Am Heart J 2000;139:723-8.

53. Stout M. The Marfan Syndrome: Implications for athletes and their echocardiographic assessment. Echocardiography 2009;26(9):1075-81.

54. De Paepe A, Devereux RB, Dietz HC, et al. Revised diagnostic criteria for the Marfan syndrome. Am J Med Genet 1996;62:417-26.

55. Nienaber CA, Eagle KA. Aortic dissection: new frontiers in diagnosis and management. Circulation 2003;108:628-35.

56. Dietz HC, Pyeritz RE. Mutations in the human gene for Fibrillin-1 in the Marfan syndrome and related disorders. Hum Mol Genet 1995;4:1799-809.

57. Marsalese DL, Moodie DS, Vacante M, et al. Marfan's syndrome: natural history and long-term follow-up of cardiovascular involvement. J Am Coll Cardiol 1989;14:422-8.

58. Yetman AT, Bornemeier RA, McCrindle BW. Long-term outcome in patients with Marfan syndrome: is aortic dissection the only cause of sudden death? J Am Coll Cardiol 2003;41:329-32.

59. Basso C, Carturan E, Corrado D, Thiene G. Myocarditis and dilated cardiomyopathy in athletes: diagnosis, management, and recommendations for sport activity. Cardiol Clin 2007;25:423-429.

60. O'Connor FG, Kugler JP, Oriscello RG. Sudden death in young athletes: screening for the needle in a haystack. Am Fam Physician 1998;57:2763-70.

61. Morgera T, Di Lenarda A, Dreas L, et al. Electrocardiography of myocarditis revisited: clinical and prognostic significance of electrocardiographic changes. Am Heart J 1992;124:455-66.

62. Heidbuchel H, Panhuysen-Goedkoop N, Corrado D, et al. Recommendations for participation in leisure-time physical activity and competitive sports in patients with arrhythmias and potentially arrhythmogenic conditions. Part I: supraventricular arrhythmias and pacemakers. Eur J Cardiovasc Prev Rehabil 2006;13:475-84.

63. Timmermans C, Smeets JLRM, Rodriguez LM, et al. Aborted sudden death in the Wolff-Parkinson-White syndrome. Am J Cardiol 1995;76:492-4.

64. Zipes DP, Ackerman MJ, Estes M, et al. Task Force 7: Arrhythmias. J Am Coll Cardiol 2005;45:1354-63.

65. Pappone C, Santinelli V, Rosanio S, et al. Usefulness of invasive electrophysiologic testing to stratify the risk of arrhythmic events in asymptomatic patients with Wolff-Parkinson-White pattern: results from a large prospective long-term follow-up study. J Am Coll Cardiol 2003;41:239-44. 
66. Klein GJ, Bashore TM, Sellers TD, et al. Ventricular fibrillation in the Wolff-Parkinson-White syndrome. $N$ Engl J Med 1979;301:1080-5.

67. Biffi A, Pelliccia A, Verdile L, et al. Long-term clinical significance of frequent and complex ventricular tachyarrhythmias in trained athletes. J Am Coll Cardiol 2002;40:446-52.

68. Kapetanopoulos A, Kluger J, Maron BJ, Thompson PD. The Congenital Long QT Syndrome and Implications for Young Athletes. Med Sci Sports Exerc 2006; 38:816-25.

69. Moss AJ, Schwartz PJ, Crampton RS, et al. The long QT syndrome. Prospective longitudinal study of 328 families. Circulation 1991; 84:1136-44.

70. AHA. Exercise and acute cardiovascular events. Placing the risk into perspective. AHA Scientific statement. Circulation 2007;115: 2358-68.

71. Moss AG. Prolonged QT-interval syndrome. JAMA 1986;256:2985-7.

72. Heidbuchel H, Corrado D, Biffi A, et al. Recommendations for participation in leisuretime physical activity and competitive sports of patients with arrhythmias and potentially arrhythmogenic conditions. Part II: ventricular arrhythmias, channelopathies and implantable defibrillators. Eur J Cardiovasc Prev Rehabil 2006;13:676-86.

73. Pelliccia A, Fagard R, Bjornstad H, et al. Recommendations for competitive sports participation in athletes with cardiovascular disease: a consensus document from the Study Group of Sports Cardiology of the Working Group of Cardiac Rehabilitation and Exercise Physiology and the Working Group of Myocardial and Pericardial Diseases of the European Society of Cardiology. Eur Heart J 2005;26:1422-45.

74. Mitchell JH, Haskell W, Snell P, Van Camp SP. Task Force 8: classification of sports. J Am Coll Cardiol. 2005;45:1364-67.

75. Napolitano C, Priori SG. Brugada Syndrome. Orphanet J Rare Dis 2006;1:35.

76. Wilde AA, Antzelevitch C, Borggrefe M, et al. Proposed Diagnostic Criteria for the Brugada Syndrome: Consensus Report. Circulation 2002;106:2514-9.

77. Brugada P, Brugada J. Right bundle branch block, persistent ST segment elevation and sudden cardiac death: a distinct clinical andd electrocardiographic syndrome: a multicenter report. J Am Coll Cardiol 1992;20:1391-6.

78. Brugada J, Brugada R, Brugada P. Determinants of sudden cardiac death in individuals with the electrocardiographic pattern of Brugada syndrome and no previous cardiac arrest. Circulation 2003;108:3092-6.

79. Gussak I, Antzelevitch C, Bjerregaard P, et al. The Brugada syndrome: clinical, electrophysiological and genetic aspects. $J$ Am Coll Cardiol 1999;33:5-15.

80. Maron BJ. Mark Estes NA. Commotio Cordis. N Engl J Med 2010;362:917-27.

81. Frazer M, Mirchandani H. Commotio cordis, revisited. Am J Forensic Med Pathol 1984;5:249-51.

82. Maron BJ, Gohman TE, Kyle SB, et al. Clinical profile and spectrum of commotio cordis. JAMA 2002;287:1142-6.

83. Link MS, Wang PJ, Pandian NG, et al. An experimental model of sudden death due to low-energy chest-wall impact (commotio cordis). N Engl J Med 1998; 338:1805-11.

84. Link MS, Maron BJ, VanderBrink BA, et al. Impact directly over the cardiac silhouette is necessary to produce ventricular fibrillation in an experimental model of commotio cordis. J Am Coll Cardiol 2001;37:649-54.

85. Madias C, Maron BJ, Weinstock J, et al. Commotio cordis-Sudden cardiac death with chest wall impact. J CardiovasC Electrophysiol 2007; 18:115-22.

86. Furlanello F, Bentivegna S, Cappato R, De Ambroggi L. Arrhythmogenic effects of illicit drugs in athletes. Ital Heart J 2003;4:829-37.

87. Halabchi F. Doping in Combat Sports. In: Kordi R, Maffulli N, Wroble RR, Wallace WA (eds). Combat Sports Medicine. 1st ed. Verlag London: Springer. 2009; Pp:55-72.

88. Halabchi F. Doping in Athletes. Hakim 2007;10:1-12. [Persian]

89. Maron BJ, Thompson PD, Ackerman MJ, et al. Recommendations and considerations related to preparticipation screening for cardiovascular abnormalities in competitive athletes: 2007 update: A scientific statement from the american heart association council on nutrition, physical activity, and metabolism: endorsed by the American College of Cardiology Foundation. Circulation 2007;115:1643-55.

90. Chaitman BR. An Electrocardiogram Should Not Be Included in Routine Preparticipation Screening of Young Athletes. Circulation 2007;116;2610-15

91. Vasheghani Farahani A, Asheri1 H, Alipour S, Amirbeigloo A. Pre-participation Cardiovascular Screening of Elderly Wrestlers. Asian J Sports Med. 2010;1:29-34.

92. Maron BJ, Bodison SA, Wesley YE, et al. Results of screening a large group of intercollegiate competitive athletes for cardiovascular disease. J Am Coll Cardiol 1987;10:1214-21. 
93. Maron BJ, Estes NAM III, Maron MS, et al. Primary prevention of sudden death as a novel treatment strategy in hypertrophic cardiomyopathy. Circulation 2003;107:2872-5.

94. IOC Medical Commission. IOC preparticipation cardiovascular screening. December 10, 2004. Available at: http://multimedia.olympic. org/pdf/en_report_886.pdf. Access date: November 28, 2010.

95. Corrado D, Pelliccia A, Bjornstad HH, et al. Cardiovascular pre-participation screening of young competitive athletes for prevention of sudden death: proposal for a common European protocol: consensus statement of the Study Group of Sport Cardiology of the Working Group of Cardiac Rehabilitation and Exercise Physiology and the Working Group of Myocardial and Pericardial Diseases of the European Society of Cardiology. Eur Heart J 2005;26:516-24.

96. Pelliccia A, Maron BJ. Preparticipation cardiovascular evaluation of the competitive athlete: perspectives from the 30-year Italian experience. Am J Cardiol 1995;75:827- 9.

97. Thompson PD, Levine BD. Protecting athletes from sudden cardiac death. JAMA 2006;296:1648-50.

98. Myerburg RJ, Vetter VL. Electrocardiograms should be included in preparticipation screening of athletes. Circulation 2007;116:2616-26.

99. Kelly BS, Mattu A, Brady WJ. Hypertrophic cardiomyopathy: electrocardiographic manifestations and other important considerations for the emergency physician. Am J Emerg Med. 2007;25:72-9.

100. Panza JA, Maron BJ. Relation of electrocardiographic abnormalities to evolving left ventricular hypertrophy in hypertrophic cardiomyopathy during childhood. Am J Cardiol 1989;63:1258-65.

101. Ryan MP, Cleland JG, French JA, et al. The standard electrocardiogram as a screening test for hypertrophic cardiomyopathy. Am J Cardiol 1995;76:689-94.

102. Gemayel C, Pelliccia A, Thompson PD. Arrhythmogenic right ventricular cardiomyopathy. J Am Coll Cardiol 2001;38:1773-81.

103. Marcus FI. Electrocardiographic features of inherited diseases that predispose to the development of cardiac arrhythmias, long QT syndrome, arrhythmogenic right ventricular cardiomyopathy/dysplasia, and Brugada syndrome. J Electrocardiol 2000;33:S1-S10.

104. Marcus FI. Prevalence of T-wave inversion beyond V1 in young normal individuals and usefulness for the diagnosis of arrhythmogenic right ventricular cardiomyopathy/dysplasia. Am J Cardiol 2005;95:1070-1.

105. Rowland T. Prevention of sudden cardiac death in young athletes: controversies and conundrums. Med Sport Sci 2011;56:171-86

106. Halabchi F, Reiskarami SR. Pre-participation examination in children. Iran J Pediatr 2006;16:485-96. [Persian]

107. List of continents by population. Available at: http://www.worldatlas.com/geoquiz/thelist.htm. Access date: Jan 5, 2011.

108. United Nations. World Population Propsects: 2006 revision, New York: United Nations publications; 2007, Pp:54-9. Available at: http://www.un.org/esa/population/publications/wpp2006/WPP2006_Highlights_rev.pdf. Access date: Jan 5, 2011.

109. Wikipedia. List of countries by GDP (nominal) per capita. Available at: http://en.wikipedia.org/wiki/List_of_countries_by_GDP_(nominal)_per_capita. Access date: Jan 5, 2011.

110. Wikipedia. Ethnic groups in Asia available at: http://en.wikipedia.org/wiki/Ethnic_groups_in_Asia. Access date: Jan 5, 2011.

111. Cho Y, Park T, Yang DH, et al. Arrhythmogenic right ventricular cardiomyopathy and sudden cardiac death in young Koreans. Circ J 2003;67:925-8.

112. Miyasaka Y, Tsuji H, Yamada K, et al. Prevalence and mortality of the Brugada-type electrocardiogram in one city in Japan. J Am Coll Cardiol 2001;38:771-4.

113. Matsuo K, Akahoshi M, Nakashima E, et al. The prevalence, incidence and prognostic value of the Brugada-type electrocardiogram: a population-based study of four decades. J Am Coll Cardiol 2001;38:765-70.

114. Bigi MA, Aslani A, Shahrzad S. Prevalence of Brugada sign in patients presenting with palpitation in southern Iran. Europace 2007;9:252-5. 